\title{
PROBLEMATIKA SONARAVNEGA RAZVOJA V \\ SLOVENSKEM ALPSKEM SVETU (NA PRIMERU RATEŠKE POKRAJINE)
}

\author{
Darko Radinja*
}

Izvleček

UDK 504:338.43(234.3 Rateče)

Poročilo osvetljuje obseg in strukturo nekdanje agrarne preobrazbe obravnavane alpske pokrajine predvsem z vidika hudourniške problematike. $Z$ okoljevarstvenega vidika se dotika njenih navzkrižij tudi $v$ zadnjih desetletjih.

Ključne besede: alpska pokrajina in sonaravni razvoj, agrarizacija in hudourniška dinamika, deagrarizacija in suburbanizacija, varstvo okolja,

\section{THE PROBLEMS OF SUSTAINABLE DEVELOPMENT IN THE ALPINE WORLD OF SLOVENIA \\ (THE CASE OF RATEČE AREA)}

\section{Abstract}

The paper illuminates the extent and structure of the onetime agrarian transformation of the Alpine area under discussion from the aspect of torrent problems. As to environmental protection, its controversies of the last decades are also tackled.

Key words: alpine area and sustainable development; agrarization and torrent dynamics; abandoning of agrarian activities and suburbanization; environmental protection.

\footnotetext{
${ }^{*}$ Dr., prof.,odd. za geogr. FF v pokoju, Grintovška 1, 1000 Ljubljana, Slovenija
} 


\section{UVOD}

Rateško pokrajino je iz naravne v kulturno spremenila njena agrarna preobrazba, ki je bila splošna in precej temeljita. Je hkrati najstarejša in tudi najdlje trajajoča, čeprav se je začela razmeroma pozno, domnevno šele sredi 12. stol. (Kos 1955), a je sklenjeno trajala kljub vsemu približno osem stoletij. Ni bila sicer nagla, prav zaradi tega pa je bila bolj organska in izkustveno preverjena, kar je okoljsko še posebej pomembno.

Višek je dosegla v prejšnjem stoletju, verjetno pred sto leti, če sklepamo po številu prebivalstva in po zemljiški strukturi pokrajine. Franciscejski kataster izpred več kot 150 let kaže, da so kmetijska tla zajela dobro polovico $(52,2 \%)$ celotne Rateške pokrajine. Ta pa se ujema $\mathrm{z}$ obsežno katastrsko občino, veliko približno $50 \mathrm{~km}^{2}$, ki sega na severni strani do razvodnega slemena Karavank in na južni do razvodnega grebena Julijskih Alp, njeno jedro pa je v vmesnem dolinskem svetu, ki pripada najvišjemu delu Zgornje Savske doline in onstran komaj opaznega dolinskega razvodja še sosednjemu povirju Belega potoka, pritoka Ziljice. Obsega potemtakem razvodni svet med Savo in Dravo, kar ji daje dobro prometno lego. Medtem ko dolinski svet (dno glavne doline) ne obsega niti desetine celotne pokrajine $(6 \%)$, zavzema karavanški približno četrtino (24 \%), julijski pa več kot dve tretjini (70 \%).

Zunaj neposredne kmetijske rabe se je na približno četrtini celotne pokrajine $(24,3$ \%), na t.i. absolutnih gozdnih tleh, ki za agrarno rabo niso prišla v poštev (risba 1), obdržal gozd. Danes ga pojmujemo kot varovalni, ki je pomemben za ohranjanje naravnega ravnotežja celotne pokrajine. Ostalo dobro petino površja $(21,5 \%)$ sestavlja gol, skalnat in za kmetijsko rabo prav tako neuporaben visokogorski svet. Agrarna doba ga je označevala za nerodovitnega, danes ga seveda vrednotimo bistveno drugače, sicer ga ne bi zavarovali kot narodni park (TNP). Pomemben pa ni le sam po sebi, temveč tudi za osrednji, dolinski del pokrajine. Med drugim je povirni svet najbolj namočen in izvorišče čistih vodnih virov, ki so v današnjem času čedalje pomembnejši. Ta, po stari agrarni terminologiji neploden svet ni pomemben za celotno pokrajino le v dobrem, temveč tudi v slabem, saj imajo v njem izvorišče tudi hudourniki. Prav ti so prepričljivo svarilo, ki nazorno opozarja, do kod je agrarna in druga raba še smiselna in upravičena in kje ne. Še več! Hudourniško dinamiko moramo jemati kot občutljivo merilo za naravno ravnotežje pokrajine, ki je omajano, ko se hudourniška dinamika krepi in obratno. Posebno pozornost je zato kazalo nameniti prav hudourniškim pojavom. Da je njihova okoljska problematika še $v$ marsičem odprta, so potrdile podrobne raziskave. 
Risba 1: Rateče - zemljiške kategorije. Spreminjanje agrarne rabe

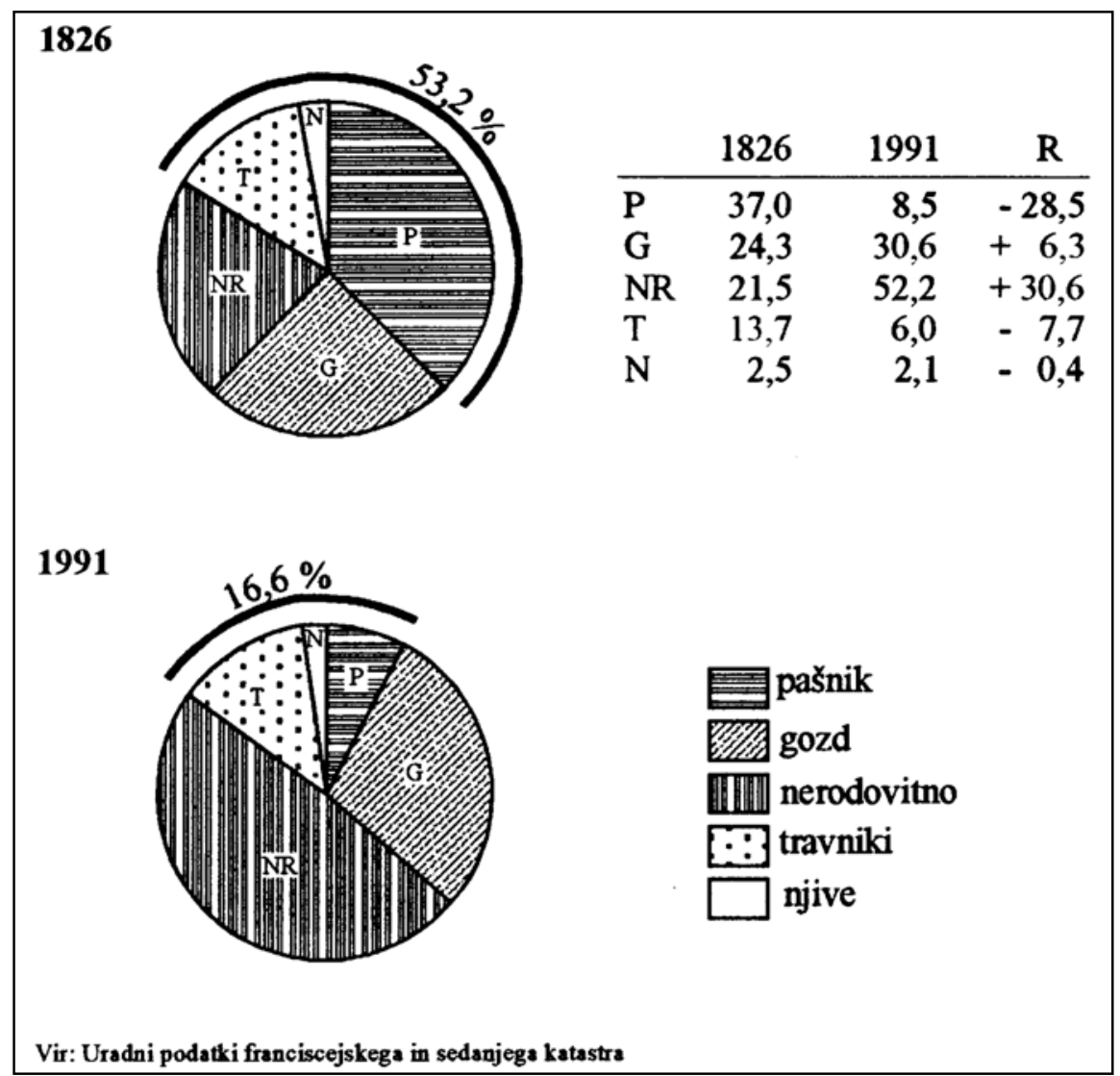

Na splošno namreč velja, da je agrarna preobrazba naših pokrajin segla $\mathrm{v}$ preteklosti marsikje predaleč, kar je prizadelo predvsem gozd, ki bi se po sedanjem pojmovanju moral ohranjati kot varovalni gozd, kar posebno velja za reliefno dinamični svet alpske pokrajine. $\mathrm{V}$ tem namreč pogosto iščemo vzroke za preveliko denudacijsko, erozijsko in drugo dinamiko, vključno s hudourniško, usadno in poplavno. Preden skušamo odgovoriti, kako je bilo s tem v Rateški pokrajini, si oglejmo, kakšne kategorije kmetijskih tal so se uveljavile na tisti polovici celotne pokrajine, ki jo je gozdu iztrgala agrarizacija.

Daleč največ vseh kmetijskih tal je pašnikov, skoraj tri četrtine $(73,8 \%)$, veliko manj travnikov, približno šestina $(17,5 \%)$, in daleč najmanj njiv, komaj dvajsetina (5\%). Čim intenzivnejša je raba, tem manj je obsežna. Takšna struktura kmetijskih zemljišč 
prav gotovo ni odsevala življenjskih potreb, saj nudi mnogo premalo zemlje za žita in druge poljščine, nesorazmerno veliko pa za prirejo živine oziroma mleka in mesa. Zakaj tako? Struktura zemljiških površin ni bila namreč odsev potreb, pač pa naravnih možnosti oziroma nujnega vsestranskega prilagajanja naravi, ker drugega tradicionalno kmetijstvo pač ni zmoglo. Iz tega sledita dva zaključka. Prvič, obseg in struktura kmetijskih tal kaže, da je imelo tradicionalno kmetijstvo obravnavane pokrajine, podobno pa tudi Zgornje Savske doline sploh, v bistvu značilnosti, ki jih danes pripisujemo sonaravnemu oziroma trajnostnemu kmetijstvu. Če ne bi bilo takšno, se skozi stoletja ne bi obdržalo. Takšno, kakršno je bilo, ni prizadevalo naravnega ravnotežja, je pa očitno prizadevalo ljudi, kar se je kazalo v njihovih (pre)skromnih življenjskih razmerah. Pri sodobnem, visoko donosnem kmetijstvu je prav obratno, prizadeti niso ljudje, pač pa narava. Kako preprečiti, da ne bi bili prizadeti ne ljudje in ne okolje, je nedvomno osnovna dilema sodobnega kmetijstva in človeške družbe sploh.

Drugi sklep nakazane problematike tradicionalnega kmetijstva je, da je bilo takšno v rateški pokrajini ves čas in je tudi še danes, čeprav se je mehaniziralo, vendar se ni hkrati tudi intenziviralo. Zato se obremenjevanje okolja ni stopnjevalo, pravzaprav se je celo omililo. Življenjske ravni pa to vseeno ni prizadelo, vendar ne po zaslugi kmetijstva, temveč nasprotnega procesa - deagrarizacije in seveda industrializacije. Ta razvoj pomeni za prej omenjeno dilemo nekakšno sintezo, ki pa je seveda protislovna, zato kvečjemu prehodna in očitno brez perspektive.

Po dolgem obdobju tradicionalnega kmetijstva se je namreč razvoj pokrajine $\mathrm{v}$ zadnjih desetletjih bistveno preusmeril in hkrati stopnjeval. Navadno ga označujemo kot industrializacijo, ki je na eni strani izzvala deagrarizacijo in na drugi (sub)urbanizacijo.Temu se tudi obravnavana pokrajina ni izognila, čeprav ju je doživljala $\mathrm{v}$ marsičem na drugačen način, bodisi zaradi lege in položaja, bodisi zaradi značilnosti družbene strukture.

Tradicionalno rateško kmetijstvo kot posledica neposrednega prilagajanja skopim naravnim osnovam ni zmoglo nuditi dovolj možnosti niti za skromno preživljanje. Ratečani so zato že od nekdaj iskali, podobno kakor v drugih delih Zgornje Savske doline, dodatne vire za preživljanje izven kmetijstva in izven domačega kraja, kar je postalo že tradicionalno. Tako so se tudi $\mathrm{v}$ prejšnjem stoletju zaposlovali $\mathrm{v}$ fužinarstvu, na Jesenicah ali v bližnji Beli Peči, pa tudi v rabeljskem rudniku, Trbižu in še kje. Ko pa so se tovrstne možnosti s splošno povojno industrializacijo na široko odprle, so se vanje vključevali brez težav, kar zgovorno potrjujejo strukturne spremembe povojnih Rateč.

Glede na prevladujoče mnenje, da je šlo agrarno kultiviranje alpskega sveta (zanj namreč gre, ko obravnavamo Rateško pokrajino) marsikje predaleč na račun varovalnega gozda, kar naj bi načelo naravno ravnotežje, manifestiralo pa $\mathrm{z}$ 
razmahom hudournikov in kasneje, posledično, tudi $\mathrm{z}$ njihovim reguliranjem. Drugače povedano, popravljati naj bi bilo treba napake ruralizacije, ki naj bi bila pretirana glede na občutljivost alpskega okolja, ne pa glede življenjskih potreb ljudi. To problematiko smo na primeru Rateške pokrajine skušali podrobneje preučiti.

\section{HUDOURNIŠKA PROBLEMATIKA}

Ni sporno, da poplave pri nas povzročajo čedalje več škode, vendar so mnenja o tem, kje so vzroki, različna. Iščejo jih bodisi pri človeku bodisi pri naravi oziroma $\mathrm{v}$ prepletanju obojega. Ne glede na to pa je očitno, da so poplave čedalje bolj škodljive. Spreminja se namreč struktura poplavnih območij, saj so čedalje bolj kultivirana. Če se jim je agrarna doba izogibala ali se je nanje kvečjemu prilagajala, pa industrijska oziroma tehnološka doba posega vanje čedalje intenzivneje. Mogoče je torej reči, da poplave ne povzročajo večje škode zato, ker bi bile čedalje obsežnejše in pogostejše, čeprav tudi to ni povsem izključeno, temveč zato, ker so njihova območja vse bolje opremljena, infrastrukturno in tudi drugače ter zato dragocenejša. Podobno velja tudi za hudourniška območja, ki so za alpski svet prav tako značilna, kakor so poplave za dolinsko-nižinskega.

Hudourniki so tudi v Zgornji Savski dolini značilna pokrajinska sestavina, Karavanke pa naše najbolj hudourniško območje, hkrati pa tudi območje $\mathrm{z}$ najštevilnejšimi hudourniškimi regulacijami (Rainer 1952, VGO 1978). Pri tem pa preučevanja hudourniških območij kažejo, kar je pomembno izhodišče, da povečini sploh niso povezana $\mathrm{z}$ agrarno rabo tal, pač pa $\mathrm{z}$ neagrarno, tisto namreč, ki vanje preveč posega, bodisi na obrobje ali vanje neposredno. Trditev naj ponazorimo $\mathrm{z}$ naslednjimi primeri.

V zgornjem in spodnjem delu Planiške doline so hudourniško destrukcijo skušali obrzdati s tehničnimi posegi. Pri hudourniku izpod Vel. Mojstrovke (2366 m) in z zaledjem v visokogorskem svetu seveda ni sledu o kakršnikoli agrarni rabi tal. Pač pa je hudournik ogrožal bližnji planinski dom Tamar, zato so ga na vznožju z odbojno pregrado preusmerili na levo stran vršaja. $S$ tem pa je regulacija nehote ogrozila agrarna tla, namreč planinski pašnik pod slapiščem Nadiže. Drugo je seveda vprašanje, ali se je hudourniško delovanje v zgornjem delu Planiške doline v zadnjih desetletjih okrepilo in zaradi tega ogrozilo planinski dom, ki so ga zgradili $\mathrm{V}$ tridesetih letih, ali pa se je erozijsko-akumulacijska amplituda hudourniške dinamike pokazala šele $v$ ustrezno daljšem obdobju (stoletju in več). Poleg tega je treba upoštevati, da so za regulacije hudournikov v današnjem času tehnične možnosti večje kakor v preteklosti. Zato takrat do njih kljub potrebam zlepa ni prišlo. Pri tem 
primeru so se hudourniški dinamiki sprva izognili tako, da so izpostavljeno stran planinskega doma raje utrdili, kakor da bi se lotili samega hudournika.

Podoben primer je v spodnjem delu Planice, kjer so regulirali dva hudournika, prvega izpod Ciprnika $(1745 \mathrm{~m})$ in drugega izpod Male Ponce $(1925 \mathrm{~m})$ na nasprotni strani doline (Beli potok). Do regulacije tudi tu ni prišlo zaradi ogroženih kmetijskih tal, temveč zaradi bližnjih športnih objektov (smučarskih skakalnic) in sosednjega planinskega doma oziroma hotela (Dom v Planici). Tudi pri teh dveh hudournikih ni bilo $\mathrm{v}$ njunem zaledju nikakršne kmetijske rabe tal, ki bi hudourniško delovanje okrepila. A tudi tu, podobno kakor v zgornjem delu Planice, regulacija ni povsem brez posledic za agrarna tla. Učinki regulirane hudourniške struge so se namreč pokazali približno dva kilometra nižje, že v glavni dolini, v neposrednem zaledju Zelencev. Odkar je pod smučarskimi skakalnicami struga utesnjena, se namreč nanosi $\mathrm{v}$ večji meri prenašajo navzdol v bližino Zelencev, ki jih tako ogrožajo, kar je hkrati nazoren primer, kako sicer koristni posegi na enem kraju sprožijo škodljive posledice na drugem.

Tretji primer je iz Jezerske (Belopeške) doline na skrajnem zahodnem robu obravnavane pokrajine oziroma katastrske občine, ki je danes sicer onstran državne meje. Regulacija hudournika v srednjem delu doline je na prvi pogled agrarna. Hudourniško delovanje naj bi se okrepilo, ko so višje po dolini gozd izkrčili za planinsko pašo na tako nastali planini Za Jezerom in stari planini Tamar, vendar hudourniške struge in njihova akumulacija pravzaprav ne izvirajo od tod, temveč izpod Male in Visoke Ponce $(2274 \mathrm{~m})$ na desni strani doline. Potemtakem do regulacije tudi tu ni prišlo zaradi agrarnih tal (pašnih površin nad Zgornjim Belopeškim jezerom), čeprav jim je nedvomno koristila. Dejansko je povezana $\mathrm{z}$ Jezernico (odtokom spodnjega jezera) in na njej postavljene HE, ki služi tovarni v Beli Peči. Njena vodnatost pa je odvisna od zgornjega jezera, ta pa ima čedalje manj vode, ker ga zasipava hudournik. Zato so jezero skušali obvarovati z regulacijo hudourniškega zaledja.

Še značilnejša je regulacija Trebiže, ki zbira vode na karavanških pobočjih, teče pa skozi zahodni del Rateč, ki ležijo na vznožju (risba 2). Njene hudourniške poteze naj bi okrepilo krčenje gozda v zaledju; na kar opozarjajo že ledinska imena (Spodnje Trebiže, Zgornje Trebiže) in tudi ime samega hudournika, ki priteka odtod (Trebiža). Nedvomo je, da obsežen senožetni svet zadržuje manj padavinske vode kakor gozdni. Zato ta hitreje oddrvi po strugi do vznožja oziroma vršaja, na katerem je naselje, ki ga je Trebiža že večkrat ogrozila in tudi prizadela. Že pred prvo svetovno vojno so jo morali zato regulirati. 
Risba 2: Regulacija hudourniške Trebiže v Ratečah

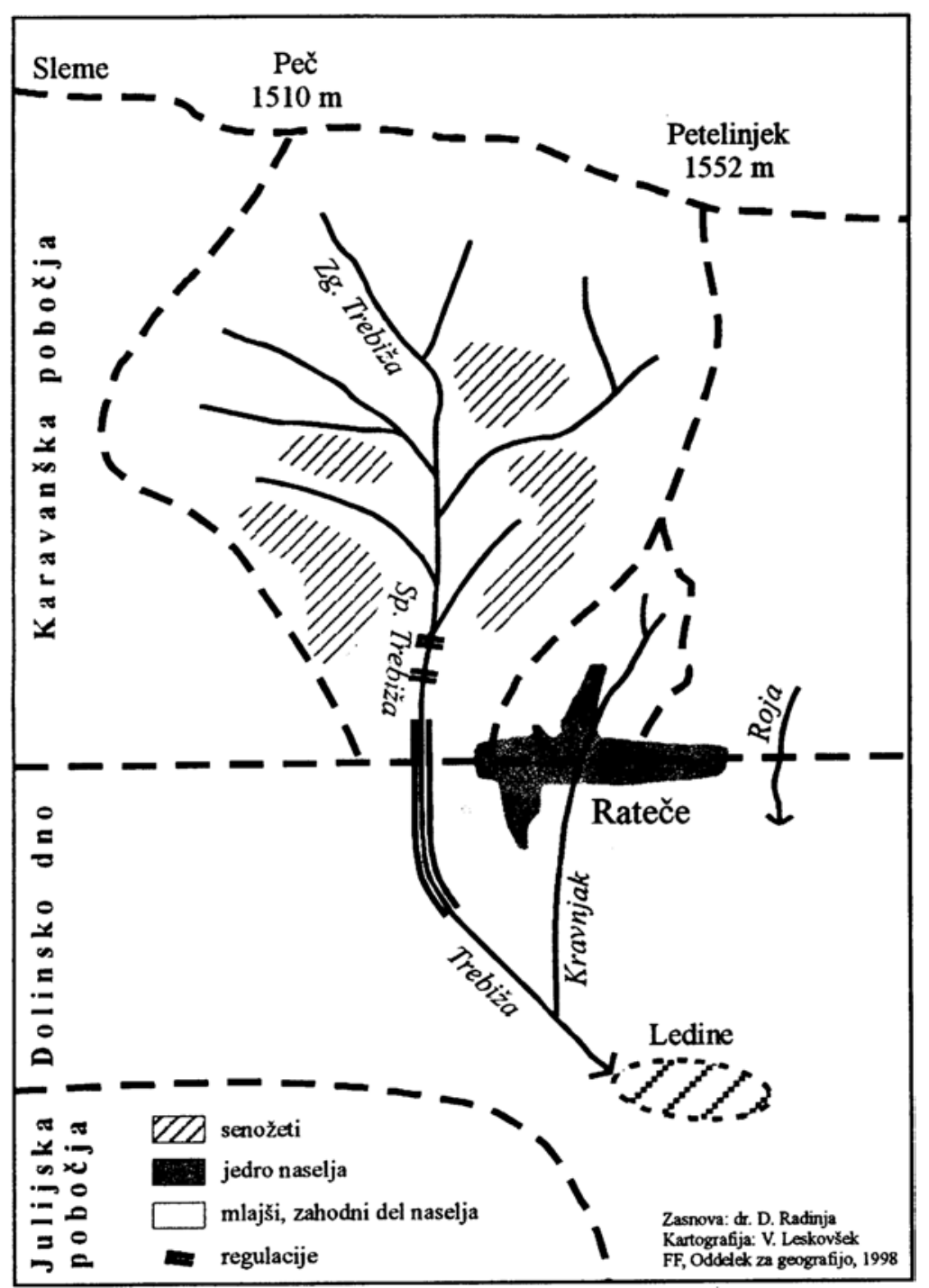


Na prvi pogled je regulacija Trebiže klasičen primer popravljanja negativnih posledic, ki naj bi jih sprožilo (pre)obsežno krčenje pobočnega gozda zaradi širjenja agrarnih tal. Ta so bila privlačna že zaradi bližine naselja, predvsem pa zaradi ugodnih naravnih osnov (prisojna in gladka ter s preperelinsko odejo prekrita pobočja), ki so kot nalašč za senožeti. Vseeno pa ostaja vprašanje, koliko je agrarna raba tal okrepila hudourniške značilnosti in koliko gre za njihovo naravno dinamiko, kakršna se pokaže šele v daljšem časovnem obdobju.

Opozoriti velja namreč na naslednje. Nikakor ni naključje, da so Rateče nastale ob manjšem Kravnjaku, ne pa ob večji Trebiži; prvi teče na vzhodni strani vršaja, druga na zahodni. Očitno je pri namestitvi naselja odločala večja varnost ob mirnejšem, čeprav manjšem potoku kakor ob večjem, toda bolj hudourniškem, kajti prvi zbira vode $\mathrm{z}$ nižjih pobočij, drugi z višjih. Šele kasneje, ko so se Rateče širile, se je zahodni del preveč približal Trebiži in se ji tako izpostavil. Regulirali so jo potemtakem zaradi naselja, ne pa kmetijskih površin, čeprav je regulacija nedvomno koristila tudi njim. Pomembnejše pa je vprašanje, ali se je hudourniška dinamika Trebiže sploh stopnjevala, ali pa je šlo le za ekstremno amplitudo njenega delovanja $\mathrm{V}$ tistem obdobju, kar se pokaže šele čez čas.

Že navedeni primeri kažejo, da hudourniška problematika očitno ni tako preprosta, kakor je videti na prvi pogled in kakor jo običajno interpretirajo. Ni je mogoče zadovoljivo osvetliti zgolj $\mathrm{v}$ okviru agrarnega kultiviranja pokrajine in njegovih posledic pa tudi ne s krčenjem gozda zaradi fužin. Analizirani primeri namreč kažejo, da je do regulacije hudournikov prišlo, ko se je na njihovem obrobju pojavila neagrarna raba tal, ki je tako dragocena, da so regulacije upravičene, medtem ko agrarna raba očitno ni bila takšna. Pravzaprav niti ni bistveno, kakšna raba je pripeljala do hudourniških regulacij, pomembneje je, ali je naravno dinamiko hudournikov stopnjevalo preširoko agrarno kultiviranje njihovih zaledij. Pravkar nakazani primeri tega ne dokazujejo. Nasprotno, prej kažejo, da gre za značilnosti, ki so sestavni del ekstremnih kolebanj hudournikov samih po sebi, ki se zvrstijo v daljšem, nemara stoletnem časovnem obdobju, kakršna poznamo pri rekah in z njimi povezanih poplavah, pri hudournikih pa ne, saj zanje, v nasprotju z rekami, ni ustreznih meritev. Zato je očitno, da je treba vsak primer posebej preučiti. "Stopnjevano" hudourniško delovanje pa ni dokaz, da bi bilo agrarno kultiviranje Rateške pokrajine, bržkone pa Zgornje Savske doline sploh, pretirano in vzrok za načeto naravno ravnotežje.

Na pokrajinsko vlogo hudournikov je mogoče gledati tudi še drugače. Ta namreč ni bila le negativna, temveč tudi pozitivna, tako rekoč preventivna, ko gre za krčenje gozda in širjenje kmetijskih tal. Njihova, večkrat kar grozljiva dinamika naj bi že od vsega začetka zgovorno svarila, s tem pa posredno tudi preprečevala, da bi prihajalo do pretiranega krčenja gozda. Zaradi mnogo večje pokrajinske dinamike se namreč alpska narava naglo in neposredno odziva, zato so posledice in povezave očitne. Do 
pretiravanja je kljub temu sprva sicer tu in tam prihajalo, vendar ne do vznemirljivih oblik. Osnovno ravnotežje se je namreč moralo ohranjati, da je agrarna doba preživela. V dolinskem svetu ta problematika ni bila živa, za višji svet pa so potrebne podrobne preučitve, kajti računati je, če drugega ne, z lokalnimi razlikami.

\section{NOVEJŠA PREOBRAZBA POKRAJINE}

Medtem ko so bila v obdobju agrarnega kultiviranja naših pokrajin v ospredju vprašanja naravnega ravnotežja zaradi krčenja gozda in z njim povezana intenzivnost denudacijske, erozijske, hudourniške in druge dinamike, pa v zadnjih desetletjih stopajo čedalje bolj $\mathrm{v}$ ospredje druga, na prvem mestu zlasti posledice naglega transformiranja stare agrarne pokrajinske strukture $\mathrm{v}$ neagrarno ter $\mathrm{z}$ njo povezane spremenjene oblike obremenjevanja okolja, ki se hkrati tako stopnjujejo, da postajajo kritične.

Zemljiška struktura sedanje Rateške pokrajine, povzeta po katastrskih podatkih za leto 1991 -torej približno po štirih desetletjih deagrarizacije -, kaže, da je kmetijskih tal le še slaba petina vsega površja $(19,4 \%$ ), obdelovalne zemlje manj kot desetina $(8,5 \%)$ in njivske komaj dvajsetina (5\%), dejansko pa je še toliko ni več. Očitno je, da je v zadnjih desetletjih rateško kmetijstvo zajela tako intenzivna deagrarizacija, da se je kmetijska površina zmanjšala za trikrat (od 52,3 \% leta 1826 na $16,6 \%$ leta 1991). Pri tem sta $\mathrm{z}$ okoljskega vidika najznačilnejša dva procesa - ogozdovanje $v$ višjih legah in ozelenjevanje v nižjem, dolinskem svetu. Oba sta povsem nasprotna tistim v preteklosti, ki naj bi bili najbolj vprašljivi zaradi denudacijskih, erozijskih in drugih posledic. $\mathrm{S}$ tega vidika sta oba procesa nedvomno pozitivna, saj sta pokrajinsko regenerativna. Zanimivo pa je, da se največkrat poudarja njuna druga stran, namreč z njima povezano krčenje kulturne pokrajine, kar naj bi bila slaba stran deagrarizacije. Če je prvi vidik okoljski, je za drugega vprašanje, kam bi ga bilo najbolj smiselno uvrstiti. Toda pomislek glede krčenja kulturne pokrajine ne more veljati pri naselbinskem tipu, kakršen je v Rateški pokrajini in v Zgornji Savski dolini sploh, kjer gre za dolinska naselja. Ko bi bila poleg njih še hribovska, npr. samotne kmetije na obmejnih karavanških pobočjih, ki jih pa ni, razen izjemoma, bi bil očitek, če bi se praznile, nemara upravičen.

Danes poljedelstva v Ratečah domala ni več, pa tudi obseg živinoreje se je prepolovil. Iz nekdaj poljedelsko-živinorejskega kmetijstva je tako postalo domala čisto živinorejsko, seveda močno oslabljeno. Temu ustrezna je prebivalstvena preobrazba. Rateče so namreč po podatkih za leto 1991 imele daleč največ nekmečkih gospodinjstev, več kot tri četrtine (75,8 \%), mešanih manj kot četrtino $(22,7 \%)$, medtem ko so kmečka le tri $(1,5 \%)$, dejansko pa danes tudi teh ni več. 
Značilno je, da se število rateškega prebivalstva kljub obsežni deagrarizaciji ni zmanjšalo. Še več, že tretje desetletje se celo rahlo povečuje. Vzrok za to je poleg že omenjene tradicije treba iskati $\mathrm{v}$ dobri prometni legi pokrajine in bližini delovnih mest, čeprav so Rateče med vsemi dolinskimi naselji najbolj oddaljene od Jesenic, ki so glavno zaposlitveno središče celotne Doline. Tja in v Mojstrano se iz Rateč (po podatkih za leto 1991) dnevno vozi skoraj sto ljudi, v Kranjsko Goro več kot petdeset in približno prav toliko preko meje v Belo Peč, nekaj jih dnevno odhaja na delo tudi na avstrijsko stran. Vseh dnevnih migrantov je kar 240, pa tudi v samih Ratečah je izven kmetijstva zaposlenih 38 ljudi, 130 pa je upokojencev. Slednji kažejo na že prej omenjeno tradicijo, da so Ratečani že od nekdaj iskali delo izven kmetijstva. Zaposlitev v industriji je sicer še vedno pomembna, čeprav nazaduje, odločilna pa postajata terciarno in kvartarno področje (risba 3). S tem v zvezi je značilno, da sta deleža ženske in moške delovne sile izenačena.

Slika 3: Spreminjanje zaposlitvene strukture v Ratečah 1961-1991

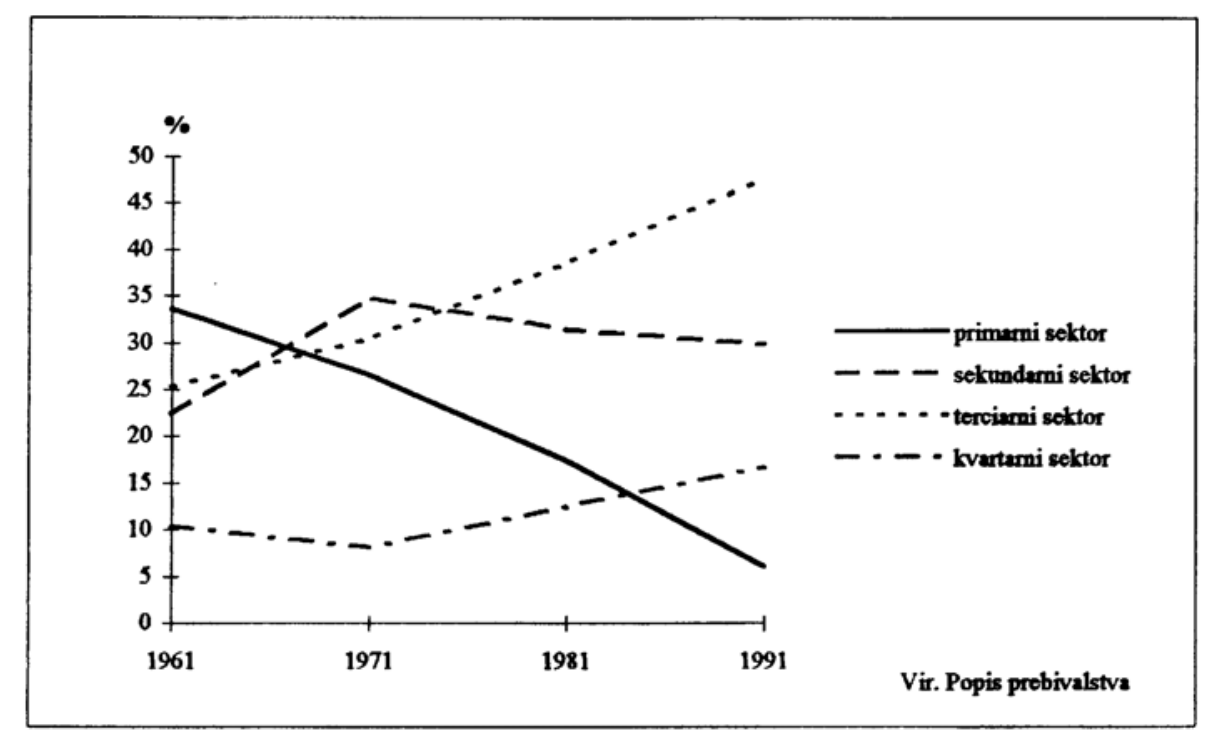


Protislovje današnjega časa je, da rateško kmetijstvo ohranja pravzaprav neagrarno prebivalstvo, namreč z dodatnim delom po službi, kar omogoča dosežena stopnja kmetijske mehanizacije. Brez nje bi kmetijstvo, pravzaprav živinoreja, še veliko bolj opešalo. Kljub temu ostaja pretežno ekstenzivno, s tem pa biološko oziroma sonaravno, kar pa je okoljsko pomembno. Poraba mineralnih gnojil je namreč zelo nizka, zaščitnih sredstev pa skoraj ne uporabljajo (Radinja 1997). Vprašanje je, kako se bodo tako specifične poteze kmetijstva sploh ohranjale. Kljub spremembam v socialni in drugi strukturi prebivalstva ostaja namreč struktura zemljiške posesti nespremenjena, kar je naslednje protislovje tega razvoja.

Z okoljskega vidika je bistveno, da so Rateče postale močno urbanizirano naselje, z ustrezno višjo življenjsko stopnjo ter večjo porabo (energije, snovi oziroma dobrin), kar je za okolje zelo zahtevno in za njegovo obremenjevanje odločilno. Številčna primerjava nekdanjega in sedanjega prebivalstva (okrog 650 preb.) zato malo pove. $\mathrm{Ob}$ skoraj nespremenjenem številu se je npr. število družin oziroma gospodinjstev skoraj podvojilo, močno se je povečalo število stanovanj in hiš, naselje pa se je razširilo tudi ozemeljsko. Obremenjevanje okolja se je zato močno okrepilo. Ko dodamo še posledice tranzitnega prometa (daleč nad 300000 vozil letno) in turističnega (nad 10000 nočitev letno), je vprašanje (pre)obremenjenosti okolja razumljivo tudi za Rateško pokrajino.

V ospredju je vsekakor onesnaževanje voda, še zlasti, ker je naselje še brez skupne kanalizacije, ki sploh omogoča čiščenje komunalnih odplak. Ker tega ni, so posledice dvakrat neugodne. Prvič, ker je pokrajina brez sklenjene vodne mreže in zato $\mathrm{v}$ primerjavi z drugimi kraji Doline precej na slabšem. Potoki, ki zbirajo vode z višjega obrobja, se namreč posamično porazgubijo v prepustna kvartarna tla na dolinskem dnu, če že ne takoj na vznožju. Čez leto se njihov tok sicer za več sto metrov skrajša ali podaljša, pri dveh potokih tudi za več kot kilometer, odvisno od njihove vodnatosti, večjega pomena pa to nima. V pokrajini tako ni možnosti, da bi odplake speljali v tekočo vodo, ki bi jih odnašala in hkrati omogočala naravno čiščenje. Ta način sicer za današnji čas, za turistično pokrajino pa še posebej, tako in tako ne ustreza več. Iz pokrajine odtekajo vode le skozi kvartarne nanose, na tej poti pa je naravno čiščenje onesnaženih voda enostransko, čeprav so debele plasti obsežen naravni filter. Zaradi razvodnega položaja pokrajine niti ni povsem jasno, kolikšen delež talne vode odteka na eno stran (savsko) in koliko na drugo (dravsko). Podzemeljsko pretakanje vode ima sicer tudi nekaj prednosti. Zaradi njega imajo Zelenci s korenško Savo vred umirjen in prav nič hudourniški režim, kar je sredi visokogorskega obrobja sicer nepričakovano, je pa ugodno.

Zaradi šibkih povirnih voda je pričakovati, da jih preobremenjujejo že manjši viri onesnaževanja, kar naj bi veljalo zlasti za vse tri potoke, ki tečejo skozi naselje (Trebižo, Kravnjak, Rojo). Podobno velja za talno vodo tam, kjer odplake prenikajo neposredno vanjo. Onesnaževanje voda tudi ni omejeno le na glavno dolino, temveč 
se začenja že v obeh stranskih (Planiški in Jezerski), medtem ko je v višjem svetu zaenkrat le izjemno. Onesnaževanje rateških voda osvetljujejo naslednji primeri.

Planinski dom v začetnem delu Planice, ki je dostopen $\mathrm{z}$ motornimi vozili in zato množično obiskan, nima niti greznice, od koder bi bilo mogoče odplake vsaj odvažati, saj premore le ponikovalno jamo. Podobno je v spodnjem delu Planice, kjer so poleg hotela tudi športni objekti. Tudi na izteku Planiške doline v glavno dolino, kjer je okrog nekdanje železniške postaje nastal del Rateč (Na postaji), sestavljen iz več stanovanjskih in počitniških domov oziroma hiš, ni veliko bolje. Večina ima sicer greznice, a vmes so tudi le ponikovalne jame. Temu se sredi glavne doline pridružujeta še dve odlagališči odpadkov. Prvo, na vzhodni strani že omenjene železniške postaje, je sicer že zapolnjeno, zato so ga prekrili in zgradili na njem športno igrišče, toda pred izpiranjem padavinske in talne vode, ki odpadke dosega, kljub vsemu ni v celoti varno. Drugo odlagališče je blizu Ledin na vznožju obeh rateških skakalnic. Njegova lega okoljsko, in tudi turistično, še manj ustreza. Na srečo ga sicer zapirajo, neugodna dediščina pa ostaja. Sicer pa Rateška pokrajina sploh nima ustreznega prostora za odlaganje kosovnih odpadkov - za te namreč gre-, kajti komunalnih v pokrajini že več let ne kopičijo več, saj jih redno odvažajo na približno $30 \mathrm{~km}$ oddaljeno občinsko deponijo nad Jesenicami. To pa je razdalja, ki je izredna ne le za slovenske razmere in zgovorno kaže, kako je v Rateški pokrajini odstranjevanje odpadkov zahtevno. Vse omenjeno so okoljsko izrazite navzkrižne točke.

V samih Ratečah so največje težave s komunalnimi odplakami, v prvi vrsti zato, ker je pokrajina brez sklenjene rečne mreže, torej brez površinske hidrološke zveze s Savo. Tako tudi ni pravih možnosti, da bi odplake spuščali vanjo, čeprav tudi to ne ustreza več. Odplake bo treba prej ali slej zbrati najprej v skupno kanalizacijo ter jih tako ali drugače speljati iz pokrajine. To pa bo že zaradi razdalje težavno, še bolj pa zato, ker bi jih bilo treba speljati mimo Zelencev in Korenškega močvirja in barja do predvidene komunalne čistilne naprave (KČN) v Kranjski Gori, kajti vmesno dolinsko dno je zavarovano kot naravni rezervat (Zelenci), kar bo še dodatno zahtevno, tudi tehnično, ne le finančno. Rateče si skoraj ne morejo omisliti lastne čistilne naprave; ne toliko zaradi tega, ker bi bilo poleg strnjenega naselja treba povezati med seboj več oddaljenih naselbinskih delov, pač pa tudi zato, ker ni kam spuščati na pol očiščeno vodo iz čistilne naprave. Te čistijo odplake namreč le do stopnje, ko jih je mogoče spuščati v naravne tokove, kjer se po naravni poti šele očistijo do konca. Ker te možnosti ni, bi bilo treba zgraditi zahtevnejšo in precej dražjo čistilno napravo, da bi vode očistila tako dobro, da bi jih bilo mogoče spuščati v šibko Trebižo, ki poleg tega še prenika.

Zagaten položaj z odplakami rešujejo zaenkrat tako, da greznice prazni komunalno podjetje z Jesenic, kamor jih na tamkajšnjo komunalno ČN tudi odvažajo, torej skozi vso Dolino več kot $25 \mathrm{~km}$ daleč. V tem pogledu so Rateče še veliko na slabšem od 
Kranjske Gore, ki sicer prav tako še nima skupne čistilne naprave, ima pa vsaj Pišnico, kamor spuščajo odplake, računajoč na njene samočistilne sposobnosti, ki pa so mnogo prešibke, kakor kaže že stopnja njene onesnaženosti. To je za turistični kraj povsem nesprejemljivo. Takšno breme nalagati hudourniku, kakršna je Pišnica, je povsem neustrezno, je kvečjemu izhod v skrajni sili, ki pa se vleče vse predolgo.

Kako težavne so v Ratečah zadrege z gospodinjskimi odplakami, kažejo različne zamisli, ki se v stiskah porajajo. Med njimi ta, da bi sredi doline, na Ledinah, ki se večkrat ojezerijo, so pa v najnižji legi, prebili neprepustno podlago ter omogočili, da bi odplake prenikale $v$ tla, kar je že tehnično zelo vprašljivo, da okoljskih posledic niti ne omenjamo, saj bi to pomenilo ne le neposredno onesnaževanje talne vode, temveč tudi samega izvira Save v bližnjih Zelencih.

\section{OBREMENJEVANJE VODA}

Zaradi pravkar nakazanih razmer je toliko zanimivejše vprašanje, kako je pravzaprav s kakovostjo rateških voda. Po splošnih hidroloških značilnostih je namreč pričakovati, da so vode onesnažene že zaradi šibkosti povirnih voda, kar naj bi veljalo predvsem za vse tri potoke, ki tečejo skozi Rateče, za Trebižo v zahodnem delu naselja, Kravnjak v srednjem in Rojo v vzhodnem delu. Vsi trije potoki so za današnje Rateče mnogo prešibki, poleg tega pa se vsi trije kmalu pod naseljem porazgubijo v tleh. Poleg 650 prebivalcev in še živine, ki po populacijskih enotah (PE) presega prebivalstvo, imajo Rateče še več kot 120 turističnih ležišč (KS Rateče 1997), sedem gostinskih obratov in vrsto počitniških hišs. Skupna obremenitev naselja dosega okoli 2000 PE, medtem ko imata Roja in Kravnjak ob nizki vodi kvečjemu nekaj litrov pretoka v sekundi in Trebiža nekaj deset litrov. Zaradi izrazite snežne retinence so nizke vode dolgotrajne, saj se iz zime razvlečejo še v zgodnjo pomlad.

Kljub neugodnim pričakovanjem so fizikalno-kemične analize rateških voda prijetno presenetile, saj so povečini še čiste oziroma le zmerno onesnažene. ${ }^{1}$ Zgovorna je zlasti primerjava Trebiže in Kravnjaka nad naseljem, pod njim in tam, kjer se na robu Ledin zgubljata v tla, Roja pa se tako in tako že prej porazgubi. Nad vasjo sta obe vodi še čisti in ju je mogoče uvrstiti v prvi kakovostni razred, čeprav so domačini opozarjali na rabo mineralnih gnojil na senožetih tik nad naseljem, vendar so skoraj brez fosfatov in nitratov. Pod naseljem sta oba potoka zmerno onesnažena. Predvidevamo, da sta bodisi v drugem oziroma drugem do tretjem kakovostnem razredu, vendar saprobne analize niso bile opravljene.

\footnotetext{
${ }^{1}$ Analize so bile opravljene v fizičnogeografskem laboratoriju Oddelka za geogr. FF v letih 1992 do 1996. Pri terenskih raziskavah so več let sodelovali tudi študenti geografije
} 
A že po krajši razdalji, dolgi približno dvesto do tristo metrov, kjer se oba potoka porazgubita $\mathrm{v}$ tleh, je kljub manjši količini vode njuna kakovost boljša. Po takšnih razmerah je mogoče sklepati, da veliko večino odplak iz naselja dejansko odvažajo, sicer bi bili obe vodi neprimerno bolj onesnaženi, če že ne mrtvi.

Razmeroma ugodno stanje kaže tudi talna voda, ki pa je malokje dostopna, saj struge niso nikjer poglobljene. V 30 m globoki vrtini (Kamnje), na izteku Planiške doline v glavno dolino, je še neoporečna, kljub že omenjenima viroma onesnaževanja $\mathrm{v}$ zgornjem in spodnjem delu Planice. Talna voda se med potjo dovolj dobro očisti, kolikor sploh gre za skupni vodni tok oziroma enoten vodonosnik, kar pa je zaradi pestre sestave kvartarnih nanosov malo verjetno. Bržkone gre tok onesnažene talne vode mimo vrtine.

Tudi glavnina izvirov Save v Zelencih je neoporečna, vendar pa razlike med njimi opozarjajo na različno zaledje, ki pa ni le planiško, kakor večinoma menijo, temveč tudi dolinsko. Manjši izvir na severnem robu Zelencev namreč kaže, da doteka vanj onesnažena voda iz vzhodnega dela naselja, imenovanega Na potokih.

Izrazita izjema je talna voda $\mathrm{v}$ vodnjaku blizu nekdanje železniške postaje, ki se od vseh drugih močno razlikuje, kar je sprva kazalo na povezavo z virom onesnaževanja $\mathrm{v}$ Ratečah, kajti vse greznice $\mathrm{v}$ naselju niso ustrezne (so premajhne in niso vodotesne), ali z bližnjo deponijo odpadkov, čeprav je že opuščena. Kasneje se je pokazalo, da je njena sestava drugačnega izvora.

Če prezremo onesnažene primesi, so rateške vode skladne z naravnimi lastnostmi pokrajine, zlasti z litološkimi in klimatskimi, so torej prepoznavno klimoconalne. So namreč ustrezno hladne, zmerno trde, če že ne mehke (6 - $8^{0}$ NT cel. trdote), vsebujejo veliko kisika, saj so z njim povečini nasičene, kar velja tudi za talno vodo. Vsebujejo malo prostega ogljikovega dioksida in tudi sulfatov ni veliko, neznatne pa so količine nitratov in fosfatov ali pa jih sploh ni. Šele razlike lahko pripišemo onesnaževanju, kar velja zlasti za sulfate, ki so tudi splošnega, alogenega izvora (onesnažene padavine).

Mehke karavanške vode so nedvomno posledica silikatnih kamnin (predvsem karbonskih glinencev in peščencev), vendar dosti večjo trdoto nimajo tudi vode na julijski strani, kljub karbonatnim kamninam (apnenci in dolomiti). Nizke trdote voda so očitno posledica tega, ker so hladne. S kisikom bogate vode imajo nedvomno tudi večjo samočistilno sposobnost, podobno vpliva živahen tok (turbulenten) in hitro obnavljanje površinske vode. Samočistilne lastnosti rateških voda so potemtakem povečini še kos sedanji stopnji onesnaževanja, čeprav gre za šibke povirne vode, ki se 
poleg tega po toku navzdol kmalu izgubljajo. Kljub vsemu je bilo za oba potoka, ki tečeta skozi glavni del naselja, pričakovati večjo onesnaženost.

Čeprav je regeneracijsko in nevtralizacijsko zmogljivost rateških voda sicer pričakovati, vseeno preseneča, da se onesnaženost Trebiže in Kravnjaka po toku navzdol najprej povečuje, nato pa že na krajši razdalji zmanjša, kajti Kravnjak prenika po približno tristo metrih in Trebiža po štiristo, izgubljata pa se na Ledinah, $\mathrm{v}$ mokrotnem svetu, bogatem s higrofilno vegetacijo, ki nedvomno pripomore $\mathrm{k}$ čiščenju obeh voda. Očitno gre za krajevno okrepljeno samočistilno sposobnost okolja, ki deluje po enakem načelu kakor v umetno ustvarjenih rastlinskih čistilnih napravah (RČN). Žal pa je učinkovita samo sezonsko, v vegetacijskem obdobju. Podobno vlogo opravlja pravzaprav tudi vegetacija okoli Zelencev, v še večji meri pa močvirje z barjem, skozi katerega teče Sava do Podkorena v približno kilometer dolgem toku. Od tam iztekajoča Sava je skoraj čista, saj je tudi po meritvah HMZ (1992-1996) v prvem do drugem kakovostnem razredu. Vse to so okoljevarstveno pomembne točke Rateške pokrajine in njenega vzhodnega roba. Ledine potemtakem s svojo higrofilno vegetacijo, zlasti pa $\mathrm{z}$ mokriščem na zahodnem robu, do koder sega Trebiža s Kravnjakom, vsaj deloma popravlja siceršnje pomanjkljivosti rateških površinskih voda. Pokrajina ima potemtakem poleg okoljsko problematičnih točk tudi ugodne, še zlasti, kjer so zgoščeno zmogljive.

Razlike v talni vodi, in tudi med izviri, kažejo, da pod dolinskim dnom očitno ni enotnega toka talne vode, kar je zaradi različne sestave kvartarnih nanosov (morenskih, jezerskih, fluvialnih in drugih) pravzaprav razumljivo. Posebnost je le že omenjena talna voda $\mathrm{v}$ vodnjaku pri nekdanji železniški postaji, ki se od drugih tako razlikuje, da je osnovnim pokrajinskim značilnostim tuja. Gre za izrazito aconalno talno vodo, ki ni drugačna zaradi morebitne onesnaženosti, saj koncentracije nitratov in fosfatov niso večje, pač pa so v njej druge snovi, ki opozarjajo na njen globinski izvor. Od drugih voda se ne razlikuje le po dvakrat do trikrat večji trdoti (nad $20^{0} \mathrm{NT}$ celokupne trdote), temveč predvsem po veliki koncentraciji ogljikovega dioksida, po večji vsebnosti sulfatov in še po nekaterih drugih primeseh (Radinja 1992-1996). Z drugimi vodami vred opozarja, da so hidrološke razmere Rateške pokrajine bolj zapletene, kakor je videti na prvi pogled, čeprav gre za povirni svet. 


\section{SKLEPNA PROBLEMATIKA}

Kaj je po vsem tem mogoče zaključiti glede obremenjenosti rateškega okolja, v prvi vrsti zaradi urbaniziranih Rateč in izrazitejše prometne in turistične funkcije pokrajine? Na eni strani je očitno, da agrarno obremenjevanje slabi, kljub mehaniziranemu, vendar hkrati ekstenzivnemu kmetijstvu, z zelo nizko energijsko porabo (Radinja 1997). Na drugi strani so očitne nove oblike onesnaževanja, ki izvirajo iz spremenjene strukture Rateč in tudi drugih neagrarnih funkcij pokrajine. Glede na stopnjo njene razvitosti $\mathrm{z}$ naseljem kot središčem, predvsem pa višje življenjske ravni prebivalcev, je logično večje obremenjevanje okolja. K manjši obremenjenosti prispeva tudi to, da Rateče niso proizvodno središče, kajti delovna mesta in z njimi potekajoče onesnaževanje okolja so praviloma drugje, medtem ko je $\mathrm{v}$ Ratečah le onesnaževanje, ki je v prvi vrsti posledica prebivanja, če izvzamemo alohtono onesnaževanje zaradi prometne in turistične vloge pokrajine.

Ker pa se je naselje močno urbaniziralo, se je obremenjevanje okolja ne le predrugačilo in stopnjevalo, temveč tudi prostorsko prestavilo. Če je bil prej ogrožen višji svet, je sedaj dolinski. Medtem ko so bile prej oblike obremenjevanja očitne, so danes tudi pritajene. Če je bila prej v ospredju erozija prsti, je sedaj onesnaževanje voda. Avtohtonemu obremenjevanju se je zaradi tranzitnega motornega prometa in turizma pridružilo še alohtono. Dolinsko okolje bi bilo danes močno preobremenjeno, ko ne bi praznili greznic in komunalnih odplak s cisternami odvažali v skoraj $30 \mathrm{~km}$ oddaljeno občinsko središče na Jesenice na tamkajšnjo komunalno ČN. Tudi gospodinjske in druge odpadke odvažajo tja na občinsko deponijo, ki je na Mežakli.

V celoti je vendarle mogoče reči, da je okolje Rateške pokrajine v bistvu še čisto in tudi privlačno, čeprav so med najočitnejšimi okoljevarstveni problemi komunalne odplake, ki pa jih za zdaj na svojevrsten način še obvladujejo. Okoljevarstvena prizadevanja domačinov so tudi sicer očitna, kar dokazuje siceršnja komunalna opremljenost, ki je hkrati tudi okoljevarstvena. Ob tem je značilno tudi zatiranje komarjev, ki so ga na začetku osemdesetih let samoiniciativno izpeljali ne po kemični, temveč biološki metodi, kar je bilo verjetno prvič pri nas. V tem delu Zgornje Savske doline je na začetku osemdesetih let nastalo tudi društvo za varstvo okolja, edino $v$ takratni jeseniški občini in med prvimi v Sloveniji. Med drugim je preprečilo, da bi v zaledju Zelencev in sredi turistične pokrajine nastal industrijski obrat, čeprav njegova spornost takrat ni bila tako očitna, kakor je danes.

V primerjavi s prejšnjo, še docela agrarno dobo se je v Rateški pokrajini stopnja sonaravnega razvoja vseeno zmanjšala. Če je bil prej sonaravni razvoj morda vprašljiv na višjem obrobju, je danes, nasprotno, na dolinskem dnu, kjer se osredotočajo nove oblike obremenjevanja okolja, nekatere tudi manj prepoznavne in nemara tudi zato manj aktualne. Bisteno pa je nemara to, da za sedanjo, komaj 
nastalo suburbano strukturo Rateč vprašanja sonaravnega razvoja (okoljevarstvenega) očitno še niso med (naj)pomembnejšimi, ker zanje eksistenčno še niso odločilna. Ne glede na to pa sedanja pokrajinskoekološka struktura ne omejuje niti najzahtevnejšega razvoja pokrajine.

\section{LITERATURA IN VIRI}

1. Althaus D., 1984: Die Oekologie des Dorfes. Berlin

2. Bohinec V., 1935: K morfologiji in glaciologiji Rateške pokrajine. Geogr. vestnik $11, \mathrm{Lj}$.

3. Dalla Valle S., Ogorevec B., 1994/95: Zelenci, Posebne strokovne podlage za ureditveni načrt,Urb.inšt. RS, Ljubljana.

4. Gams I. 1992: Prispevek k mladokvartarni geomorfologiji v Zgornjesavski dolini. Geogr.zb., 31, GI SAZU, Ljubljana.

5. Gregori J., 1980: Zelenci, izvir Save Dolinke. Kult. narav. spomeniki Slovenije, Ljubljana.

6. Kos M., 1955: Zgodovina Slovencev, Ljubljana.

7. Kunaver J., 1990: H geomorfologiji dolomitnega prevala Vršič v Julijskih Alpah, $\mathrm{GV}, \mathrm{Lj}$.

8. Lovrenčak F., 1986: Zgornja gozdna meja v Julijskih Alpah, Geogr. zb. 25, GI SAZU, Lj.

9. Melik A., 1954: Slovenski alpski svet, Slov. matica, Ljubljana.

10. Petrič M., 1990: Rateče, zgodovina vasi, Kult. in nar. spomeniki Slovenije, Ljubljana.

11. Pristov I., s sod.: Prikaz izdelave vodne bilance na Savi Dolinki, Razprave HMZ, 28, 2, Ljubljana.

12. Radinja D., 1992 - 1996: Hidrogeografske značilnosti Rateške pokrajine, ZI FF, letna poročila Raz. naloga Pokrajinska problematika slov. alpskega sveta.

13. Radinja D., 1994: Oskrba s pitno vodo v slovenskem alpskem svetu na primeru Rateč. Raz. naloga Pokrajinska problematika slov.alpskega sveta, ZI FF, Ljubljana.

14. Radinja D., 1997: Kmetijsko obremenjevanje slovenskega alpskega sveta na izbranem primeru, Dela 12, Odd. za geogr. FF, Ljubljana.

15. Rainer F., 1952: Vprašanje gozdarstva in ureditev hudournikov v Gornji Savski dolini, Gozdarski vestnik, 10, Ljubljana.

16. Stancar A., 1968: Generalni načrt za ureditev gornjesavskih hudournikov, Ljubljana Tehnično poročilo za hudournike v Ratečah: Trebiža, Kravnjak, Na Potokih in Suhi voz, Podjetje za urejanje hudournikov, Ljubljana.

- 1950 - 1970 : Arhivsko gradivo Podjetja za urejanje hudournikov, Ljubljana.

- 1978: Vodnogospodarske osnove, Zveza vodnih skupnosti Slovenije, Ljubljana. 
- 1993-1996: Kakovost voda v Sloveniji, HMZ, Ljubljana

- 1970: Zgodovina agrarnih panog. Gospodarska in družbena zgodovina Slovencev, SAZU, Ljubljana.

- 1992: Občina Rateče - Planica da ali ne? Krajevna skupnost Rateče, Rateče.

- 19971: Popisi prebivalstva 1961, 1971, 1981, 1991, Zavod RS za statistiko, Lj.

- 1986: Geol. karta, 1: 100 000, list Beljak, Geol. zav. Ljubljana, Beograd.

\title{
THE PROBLEMS OF SUSTAINABLE DEVELOPMENT IN THE ALPINE WORLD OF SLOVENIA (THE CASE OF RATEČE AREA)
}

\begin{abstract}
Summary
The area discussed lies in the northwesternmost corner of Slovenia, at the meeting point of three borders, Slovenian, Austrian and Italian. It measures $50 \mathrm{sq} \mathrm{km}$ and has a vertical drop of $1800 \mathrm{~m}$ (between $850 \mathrm{~m}$ and $2679 \mathrm{~m}$ ). Its center, Rateče with 650 inhabitants, lies in a valley.

The explicit natural dynamics of this Alpine world, especially the torrent dynamics, has been the decisive factor of holding back the traditional agrarian transformation, so that the latter could not become excessive although it spread over a gross half of the area. Therefore, it did not endanger the natural balance. Woods have been preserved on a quarter $(24 \%)$ of the area, while a gross fifth $(22 \%)$ belongs to a barren, prevailingly rocky and mainly high-mountainous world. In that half of the area which was taken from the woods by the agrarization, by far the greatest percentage belongs to the least intensive use, i.e. to alpine pastures (74\%), much less to foothill meadows $(18 \%)$, and by far the least portion to valley fields $(5 \%)$ as the most intensive form of use.
\end{abstract}

Such a structure of the lands did not reflect the life needs which were very modest and even unsatisfactory, but from an urgent and omni-sided adaptation to the hard natural conditions of the Alpine environment. Traditional agriculture, which was in practice from the mid- $12^{\text {th }} \mathrm{C}$. to the mid $-20^{\text {th }} \mathrm{C}$., had the features which are now considered as sustainable. Thus, as a rule, overpollution of the Alpine environment did not occur and the torrent dynamics did not intensify.

The situation has radically changed only in the last few decades. The area underwent rapid abandoning of agrarian activities, which, however, was not accompanied by depopulation. The labour got employed in the nearby industrial and other centers, where the workers commute daily, to the distance even up to $30 \mathrm{~km}$ and also beyond 
the state border. Concurrently the population structure changed essentially: by far the most numerous are non-peasant households (76\%), less than a quarter (23\%) are mixed, and only one percent are peasant households.

Although the agriculture got mechanized it did not intensify and has mainly been kept going by non-agrarian population or mixed households. Crop farming has almost died away and the number of livestock declined to a half. The extent of farming lands has been reduced by three times, from $52 \%$ to $17 \%$. The greening has spread over the valley bottom and higher altitudes have been overgrown with woods.

Since Rateče has become intensely urbanized, the environmental pollution has assumed a different form and has been gradually intensified. If higher altitudes were endangered before, nowadays, it is the valley that is endangered. While earlier the forms of pollution were evident, they are also concealed nowadays. Soil sollution was the worst form before, while now, it is water pollution. Due to transit transport and tourism, autochtonous pollution has also been merged with allochtonous pollution. The valley environment would be heavily polluted nowadays, were not the cesspools emptied and communal sewage removed by means of tank lorries to the communal processing plant at the almost $30 \mathrm{~km}$ distant municipal center (Jesenice). Also the household- and other refuse are transported to the municipal dump at Jesenice. In such a way, the environment which is actually still unpolluted and attractive, is being maintained. This corner of Slovenia is also famous for its sports evens, like world championships in ski jumps (Planica). 